\title{
Correction to: Sport entrepreneurship: A synthesis of existing literature and future perspectives
}

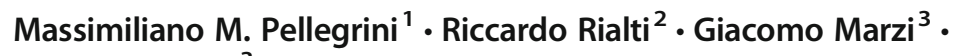
Andrea Caputo ${ }^{3}$

Published online: 14 May 2020

(C) Springer Science+Business Media, LLC, part of Springer Nature 2020

\section{Correction: International Entrepreneurship and Management Journal.} https://doi.org/10.1007/s11365-020-00650-5

The original version of this article was revised. The table below shows the incorrect and correct columns.

The online version of the original article can be found at https://doi.org/10.1007/s11365-020-00650-5

Massimiliano M. Pellegrini

massimiliano.pellegrini@uniroma2.it

1 Management and Law Department - School of Economics, University of Rome "Tor Vergata", Rome, Italy

2 Department of Science for Business and Economics, University of Florence, Florence, Italy

3 Lincoln International Business School, University of Lincoln, Lincoln, UK 
Page No.

Section

Paragraph No.

Line No.

Page 1

Abstract

Paragraph 1

Line 11

Page 2

Introduction

Paragraph 4

Line 4

Page 3

Introduction

Paragraph 7

Line 2

Page 3

Introduction

Paragraph 7

Line 19

Page 3

Introduction

Paragraph 8

Line 5

Page 4

Introduction

Paragraph 9

Line 2

Page 4

Introduction

Paragraph 10

Line 11

Page 4

Introduction

Paragraph 10

Line 12

Page 4

Introduction

Paragraph 11

Line 7

Page 4

Introduction

Paragraph 11

Line 12

Page 5

Introduction

Paragraph 11

Line 2

Page 5

Introduction

Paragraph 11

Line 3

Page 5

Introduction

\section{Incorrect}

which

that

aspect

aspects

which

that

may

can

to surely acquire

surely prone to acquire

which

that

which

that

for

and for

on the one hand,

DELETE

manage

the management of

one the one hand,

DELETE

are

is

which

that 
(continued)

Page No.

Section

Paragraph No.

Line No.

Paragraph 15

Line 6

Page 6

Bibliometric Analysis

Paragraph 2

Line 2

Page 6

Bibliometric Analysis

Paragraph 2

Line 6

Page 6

Bibliometric Analysis

Paragraph 2

Line 6

Page 6

Bibliometric Analysis

Paragraph 3

Line 5

Page 7

Bibliometric Analysis

Paragraph 4

Line 2

Page 7

Bibliometric Analysis

Paragraph 4

Line 10

Page 7

Bibliometric Analysis

Paragraph 6

Line 3-4

Page 7

Bibliometric Analysis

Paragraph 8

Line 1

Page 7

Bibliometric Analysis

Paragraph 8

Line 1

Page 7

Bibliometric Analysis

Paragraph 8

Line 2

Page 7

Bibliometric Analysis

Paragraph 8

Line 4

Page 7

Bibliometric Analysis

Paragraph 8
Incorrect

Correct

of

DELETE (mapping $\theta f$ the knowledge)

and

and of

the

,but the

permed

entered

was

is

paper

papers

set iterated routine

set of iterated routines

A sectoral map

In a sectoral map

where however,

DELETE

still

DELETE

between

DELETE

In addition, the cluster

DELETE 
(continued)

Page No.

Section

Paragraph No.

Line No.

Line 5-6

Page 8

Results of the bibliometric activity indicators

Paragraph 2

Line 3

Page 8

Results of the bibliometric activity indicators

Paragraph 3

Line 2

Page 8

Results of the bibliometric activity indicators

Paragraph 3

Line 6

Page 8

Results of the bibliometric activity indicators

Paragraph 4

Line 5

Page 8

Results of the bibliometric activity indicators

Paragraph 4

Line 7

Page 8

Results of the bibliometric activity indicators

Paragraph 4

Line 7

Page 8

Results of the bibliometric activity indicators

Table 1

Endnotes

Page 12

Results of the VOS analysis and the systematic literature review

Paragraph 1

Line 4

Page 13

Title

Page 13

Cluster 1 - green: Sport entrepreneurship theory and factors triggering
Incorrect

Correct

knowledge base diversity

in an aggregate way.

201

2015

published in form

published from

fondant

fundamental

in relation to of number

of papers

DELETE

even if with

But with

represent

still collect

The paper in the Scopus database is still listed with the year of the online publication. However, the current version from the publisher page is dated (2015). In order to avoid distortions or confusion the citation has been kept as the original version in the Scopus database.

clustered

obtained

Please, notice that this endnote should be related to Paco et al. (2013) paper in the table
Cluster 1

sportsmen
Cluster I

sportspeople 
(continued)

Page No.

Section

Paragraph No.

Line No.

sportspeople entrepreneurial propensity

Paragraph 1

Line 10

Page 14

Cluster 1 - green: Sport entrepreneurship theory and factors triggering

sportspeople entrepreneurial propensity

Paragraph 2

Line 14

Page 15

Cluster 1 - green: Sport entrepreneurship theory and factors triggering

sportspeople entrepreneurial propensity

Paragraph 5

Line 16

Page 15

Cluster 1 - green: Sport entrepreneurship theory and factors triggering

sportspeople entrepreneurial propensity

Paragraph 6

Line 5

Page 15

Cluster I - green: Sport entrepreneurship theory and factors triggering

sportspeople entrepreneurial propensity

Paragraph 6

Line 5

Page 16

Cluster II- blue: Environmental factors and external conditions fostering sport

Entrepreneurship

Paragraph 1

Line 9

Page 16

Cluster II- blue: Environmental factors and external conditions fostering sport

Entrepreneurship

Paragraph 1

Line 12

Page 16

Cluster II- blue: Environmental factors and external conditions fostering sport

Entrepreneurship

Paragraph 1

Line 14

Page 16

Cluster II- blue: Environmental factors and external conditions fostering sport

Entrepreneurship

Paragraph 4
Incorrect

Correct

players

players"

$\mathrm{EO}$ and EI.

Entrepreneurial

Orientation and

Entrepreneurial

Intentions.

competitive

and competitive

most

most of

people passionate

passionate people

is

is,

which

that

goods

such goods and services 
(continued)

Page No.

Section

Paragraph No.

Line No.

Line 8

Page 16

Cluster II- blue: Environmental factors and external conditions fostering sport

Entrepreneurship

Paragraph 5

Line 1

Page 17

Cluster II- blue: Environmental factors and external conditions fostering sport

Entrepreneurship

Paragraph 6

Line 1

Page 17

Cluster II- blue: Environmental factors and external conditions fostering sport

Entrepreneurship

Paragraph 7

Line 5

Page 17

Cluster II- blue: Environmental factors and external conditions fostering sport

Entrepreneurship

Paragraph 8

Line 4

Page 17

Cluster III - yellow: Sport entrepreneurial education

Paragraph 1

Line 3

Page 17

Cluster III - yellow: Sport entrepreneurial education

Paragraph 2

Line 4

Page 17

Cluster III - yellow: Sport entrepreneurial education

Paragraph 2

Line 9

Page 17

Cluster III - yellow: Sport entrepreneurial education

Paragraph 2

Line 10
Incorrect

Correct

concentred

focused

how

how the

product

products

university

universities

was

is

This research tried to identify who between male students enrolled in a sport schools and girls enrolled in a business schools was showing higher entrepreneurial orientation or intention.

though

DELETE RED PARTS:

This research tried to identify who between male students enrolled in a sport schools and Female enrolled in a business schools showing higher entrepreneurial orientation or intention.

Through 
(continued)

Page No.

Section

Paragraph No.

Line No.

Page 18

Cluster III - yellow: Sport entrepreneurial education

Paragraph 2

Line 19

Page 18

Cluster III - yellow: Sport entrepreneurial education

Paragraph 2

Line 20

Page 18

Cluster III - yellow: Sport entrepreneurial education

Paragraph 2

Line 21

Page 18

Cluster III - yellow: Sport entrepreneurial education

Paragraph 2

Line 25

Page 18

Cluster III - yellow: Sport entrepreneurial education

Paragraph 2

Line 29

Page 18

Cluster III - yellow: Sport entrepreneurial education

Paragraph 2

Line 34

Page 18

Cluster III - yellow: Sport entrepreneurial education

Paragraph 2

Line 37-38

Page 18

Cluster III - yellow: Sport entrepreneurial education

Paragraph 2

Line 39

Page 18

Cluster III - yellow: Sport entrepreneurial education

Paragraph 2

Line 39

Page 18

Cluster III - yellow: Sport entrepreneurial education

Paragraph 2

Line 40
Incorrect

Correct

intention

intentions

higher attention

higher levels of attention

specifically tackling

DELETE

, they

DELETE

no difference

related to gender

no difference related

to gender was detected

intention

intentions

on the PLS-MP algorithms which show

on PLS-MP algorithms show

intentions

intention

The entrepreneurial 
(continued)

Page No.

Section

Paragraph No.

Line No.

Page 18

Cluster III - yellow: Sport entrepreneurial education

Paragraph 2

Line 40

Page 18

Cluster III - yellow: Sport entrepreneurial education

Paragraph 3

Line 2-3

Page 18

Cluster III - yellow: Sport entrepreneurial education

Paragraph 3

Line 3

Page 18

Cluster III - yellow: Sport entrepreneurial education

Paragraph 3

Line 4

Page 19

Cluster III - yellow: Sport entrepreneurial education

Paragraph 5

Line 2

Page 19

Cluster III - yellow: Sport entrepreneurial education

Paragraph 5

Line 3

Page 19

Cluster III - yellow: Sport entrepreneurial education

Paragraph 5

Line 8

Page 19

Cluster III - yellow: Sport entrepreneurial education

Paragraph 5

Line 9

Page 19

Cluster IV - red: Social role of sport entrepreneurship and its implications

Paragraph 1

Line 6

Page 19

Cluster IV - red: Social role of sport entrepreneurship and its implications

Paragraph 1

Line 7
Incorrect

Correct

instead, it derives

this derives

(i.e. why sport courses

students show

higher entrepreneurial orientation)

concerning adopting

concerning and adopting

model

models

Ratten

Ratten's

points out

stresses

Hard

Heavy

to develop

developing

for-profit entrepreneurial ventures and social entrepreneurial ventures.

case of the firsts ones 
(continued)

Page No.

Section

Paragraph No.

Line No.

Page 19

Cluster IV - red: Social role of sport entrepreneurship and its implications

Paragraph 1

Line 8

Page 19

Cluster IV - red: Social role of sport entrepreneurship and its implications

Paragraph 1

Line 9

Page 19

Cluster IV - red: Social role of sport entrepreneurship and its implications

Paragraph 1

Line 10-11

Page 20

Cluster IV - red: Social role of sport entrepreneurship and its implications

Paragraph 5

Line 2

Page 20

Cluster IV - red: Social role of sport entrepreneurship and its implications

Paragraph 5

Line 4

Page 20

Cluster IV - red: Social role of sport entrepreneurship and its implications

Paragraph 6

Line 5

Page 20

Cluster IV - red: Social role of sport entrepreneurship and its implications

Paragraph 6

Line 5

Page 21

Discussion of the systematic literature review and gaps for future

Research

Paragraph 1

Line 3

Page 21

Discussion of the systematic literature review and gaps for future

Research

Paragraph 1

Line 3

Page 21

Discussion of the systematic literature review and gaps for future
Incorrect

Correct

new

renewed

in respect of

to

value for community

benefits for communities

by investigating

DELETE

show

showed

to organize

to be organized

schema

schemata

which

that

which

that

need discipline, rigor, to be need discipline and rigor to be 
(continued)

Page No.

Section

Paragraph No.

Line No.

Research

Paragraph 2

Line 4

Page 22

Discussion of the systematic

literature review and gaps for future

Research

Paragraph 6

Line 14

Page 22

Discussion of the systematic literature review and gaps for future

Research

Paragraph 8

Line 1

Page 23

Discussion of the systematic literature review and gaps for future

Research

Paragraph 9

Line 14

Page 23

Discussion of the systematic literature review and gaps for future Research

Paragraph 9

Line 20

Page 24

Discussion of the systematic literature review and gaps for future

Research

Paragraph 11

Line 10

Page 24

Discussion of the systematic literature review and gaps for future Research

Paragraph 11

Line 23

Page 24

Discussion of the systematic literature review and gaps for future

Research

Paragraph 11

Line 24

Page 24

Discussion of the systematic literature review and gaps for future Research

Paragraph 11
Incorrect

Correct

Or if that

Does this difference

elements

elements

On the other hand, according

According

Literature

The literature

are specific

are the specific

how

How does

the

can

How sportspeople

How can sportspeople 
(continued)

Page No.

Section

Paragraph No.

Line No.

Line 28

Page 26

Discussion of the systematic

literature review and gaps for future

Research

Paragraph 17

Line 2

Page 26

Discussion of the systematic

literature review and gaps for future

Research

Paragraph 18

Line 1

Page 27

Conclusions and limitations

Paragraph 1

Line 2
Incorrect

Correct

which

that into how sport

management is

of the stream of research. of the several streams of knowledge is how sport
entrepreneurship 